\title{
Fetal development, and placental and maternal plasma concentrations of progesterone in the little brown bat (Myotis lucifugus)
}

\author{
W. B. Currie, Martha Blake* and W. A. Wimsatt*† \\ Department of Animal Science and *Section of Genetics and Development, Cornell University, \\ Ithaca, NY 14853-4801, U.S.A.
}

\begin{abstract}
Summary. Progesterone concentrations measured in plasma samples from 280 bats captured during pregnancy or early lactation were related to fetal attributes indicative of stage of pregnancy. Fetal weight increased exponentially from $40 \mathrm{mg}$ at crown-rump length of $6 \mathrm{~mm}$ to $2000 \mathrm{mg}$ at $23 \mathrm{~mm}$ (term). Fetal weights at term accounted for up to $35 \%$ of the weight of intact pregnant animals. Progesterone concentrations increased from $<5 \mathrm{ng} / \mathrm{ml}$ at $2 \mathrm{~mm}$ estimated crown-rump length to plateau values of $\sim 65 \mathrm{ng} / \mathrm{ml}$ (geometric means) from $16 \mathrm{~mm}$ crown-rump length until the most advanced stages of pregnancy. Mean concentration in 8 post-partum bats, most of which were actively lactating, was $8.4 \mathrm{ng} / \mathrm{ml} ; 11.6 \mathrm{ng} / \mathrm{ml}$ was measured in one animal that was carrying a wet neonate when sampled yet was still pregnant when captured $5 \mathrm{~h}$ earlier. Placental concentrations of progesterone ranged from 43 to $964 \mathrm{ng} / \mathrm{g}$ wet weight of tissue and mean values increased in a similar fashion though were about 4-fold greater than changes in plasma concentrations of the steroid. The concentrations in placental tissue were at least 15 - to 20 -fold higher than could be expected from blood contamination, indicating that placental steroidogenesis is likely to occur in this species.
\end{abstract}

Keywords: Myotis; pregnancy; progesterone; bats; placenta

\section{Introduction}

The microchiropteran, Myotis lucifugus, known as the little brown bat, is a much studied North American species. An extensive collation of biodata has been prepared by Fenton \& Barclay (1980), to which the reader is referred for a general background to this species. The animal exhibits remarkable reproductive adaptations and capacity given its flexibility in migratory habit, sensitivity to ambient thermal conditions, social behaviour and dietary practices.

Mating occurs in the fall before the females begin hibernation but torpid females may be mated repeatedly and indiscriminately throughout the winter by any active male in the hibernaculum (Wimsatt, 1945). Ovulation occurs shortly after arousal from hibernation, fertilization occurs and pregnancy begins, but at times that vary with geographic location and between individuals within a community (Tuttle \& Stevenson, 1982). The females relocate to nursery colonies, resume foraging activity and appear to select ambient conditions conducive to their pregnancies. The duration of pregnancy is 50-60 days (Wimsatt, 1945), but is influenced by the level of feeding, metabolic activity of the dams and hence body temperature. Young are born with weights of $2 \cdot 08 \pm 0 \cdot 18 \mathrm{~g}$, being $25-32 \%$ of maternal post-partum weight (Smith, 1956). The mechanism responsible for triggering parturition is not known and few endocrine data are available for this species.

During initial review of this manuscript, a directly complementary study of plasma progesterone concentrations in little brown bats ( $M$. lucifugus) was published by Buchanan \& YoungLai (1986). These authors provide detailed information especially for the earliest stages of pregnancy.

†Deceased. 
The present paper describes the pattern of fetal growth and changes in plasma concentrations of progesterone during pregnancy in little brown bats.

\section{Materials and Methods}

Animals. A total of 303 female $M$. lucifugus were collected approximately twice weekly during the periods 20 May to 16 June 1981, and 12 May to 30 June 1982 . The bats were captured, by hand or in mist nets, from nursery colonies in attics and barns in the vicinity of Ithaca, NY. After capture, they were held in wire cages at $21^{\circ} \mathrm{C}$ and $55 \%$ relative humidity under $12 \mathrm{~h}$ light: $12 \mathrm{~h}$ dark subdued lighting. Most bats were killed by exsanguination within $48 \mathrm{~h}$ and usually within $12 \mathrm{~h}$ after collection. It was impracticable to train the bats to eat in captivity within this time so no food was offered; water was freely available. Some animals were held at $5^{\circ} \mathrm{C}$ in a hibernaculum for a few days then aroused by transfer to $21^{\circ} \mathrm{C}$ for at least $2 \mathrm{~h}$ before being killed.

Sampling. Animals were weighed then anaesthetized with ether, pinned out on corkboard and the ventral abdomen and thorax were opened and the ribs were reflected to expose the heart. The left ventricle was punctured with a 22-gauge needle connected to $30 \mathrm{~cm}$ of heparinized polyethylene tubing and blood was collected. This method can provide up to $400 \mu 1$, or up to $50 \%$ of total blood volume. The blood was transferred into $75 \mathrm{~mm}$ heparinized haematocrit tubes and held at $4^{\circ} \mathrm{C}$ until the plasma was separated by centrifugation and then held frozen at $-20^{\circ} \mathrm{C}$ until analysis.

The abdominal wall was reflected to expose the reproductive tract. If the uterus was $<7 \mathrm{~mm}$ in cranio-caudal length, the entire tract was removed, measured accurately then opened along the cranial margin to enable collection of the placenta and fetus. Uteri larger than $7 \mathrm{~mm}$ were opened in situ. The linear dimensions of the placenta were measured and one half was frozen on solid $\mathrm{CO}_{2}$ for subsequent analysis. The fetus was weighed and, whenever practicable, the crown-rump length (CR) was measured.

Progesterone assay. After a preliminary assessment of progesterone concentrations in two pools of plasma constructed from samples collected from animals with small $(<12 \mathrm{~mm} \mathrm{CR})$ and large $(>12 \mathrm{~mm} \mathrm{CR})$ fetuses, all samples were assayed using duplicate $5 \mu \mathrm{l}$ samples of plasma. To the $5 \mu \mathrm{l}$ of plasma, $100 \mu \mathrm{l}$ water were added and the sample was extracted with $3 \mathrm{ml}$ petroleum ether (BP 40-60) by mechanical shaking for $20 \mathrm{~min}$. The phases were allowed to separate and the solvent was decanted after freezing the aqueous portion. The solvent was evaporated in an air-stream at $45^{\circ} \mathrm{C}$. Standards were taken from ethanolic stock solutions of progesterone (Sigma Chemical Company, St Louis, MO). The remainder of the assay was as described by Fitzgerald \& Butler (1982); the only significant cross-reactivity from 18 tested steroids was exhibited by $5 \beta$-dihydroprogesterone ( $11.6 \%$ compared to progesterone). Quality control was achieved by including pools constructed from known quantities of radioinert progesterone added to bulk volumes of bat plasma that had been treated previously with charcoal at $37^{\circ} \mathrm{C}$, centrifuged and filtered. Prior addition of tritiated progesterone verified the completeness of 'stripping'. Overall recovery of added progesterone was $90-93 \%$; data were not adjusted for procedural losses. Intra- and inter-assay coefficients of variation were $6.8 \%$ and $8.7 \%$ in the three assays required for the plasma samples.

Hemi-placentas, weighing $18-70 \mathrm{mg}$, were homogenized in $13 \times 100$ tubes in $2 \mathrm{ml} 100 \mathrm{mM}-\mathrm{NH}_{4} \mathrm{HCO}_{3}$, adjusted to $\mathrm{pH} 9$ using $\mathrm{NH}_{4} \mathrm{OH}$. A Polytron homogenizer was used for a total of $30 \mathrm{sec}$ at approximately half full speed. Then $1 \mathrm{ml}$ of the homogenate was extracted by a further $30 \mathrm{sec}$ homogenization after adding $4 \mathrm{ml}$ of petroleum ether. Tubes were centrifuged at $100 \mathrm{~g}$ for $15 \mathrm{~min}$ before freezing the aqueous portion and decanting the solvent. After evaporation, the residue was dissolved in $2 \mathrm{ml}$ phosphate-buffered saline containing $1 \%(\mathrm{w} / \mathrm{v})$ bovine serum albumin. Solution of the residue was achieved by incubating at $37^{\circ} \mathrm{C}$ with periodic vortexing for $30 \mathrm{~min}$. The reconstituted extract was diluted $10-$ fold and a $100 \mu \mathrm{l}$ sample was assayed for progesterone.

\section{Results}

The stage of pregnancy in animals captured from nursery colonies cannot be determined precisely, so attributes of the conceptus and uterus were used as a basis for grouping the endocrine measurements. At presumptive early stages, it is impossible to measure CR with confidence. The craniocaudal dimension of the uterus was used to estimate fetal CR in most cases where this was $<7 \mathrm{~mm}$. In 30 cases, both $\mathrm{CR}$ and uterine length were measured and, with a single exception, the two measurements were within $1 \mathrm{~mm}$ of each other. At the very early stages when uterine length was $<1.5 \mathrm{~mm}$, there was a distinct possibility that the animals included non-pregnant or at least preimplantation specimens (see Buchanan \& YoungLai, 1986, for a detailed analysis of the early developmental stages). These smallest uteri were not opened to verify the presence of a conceptus so all animals with uteri of length $<1.5 \mathrm{~mm}$ were adjudged to be non-pregnant and the data were excluded from analysis. 


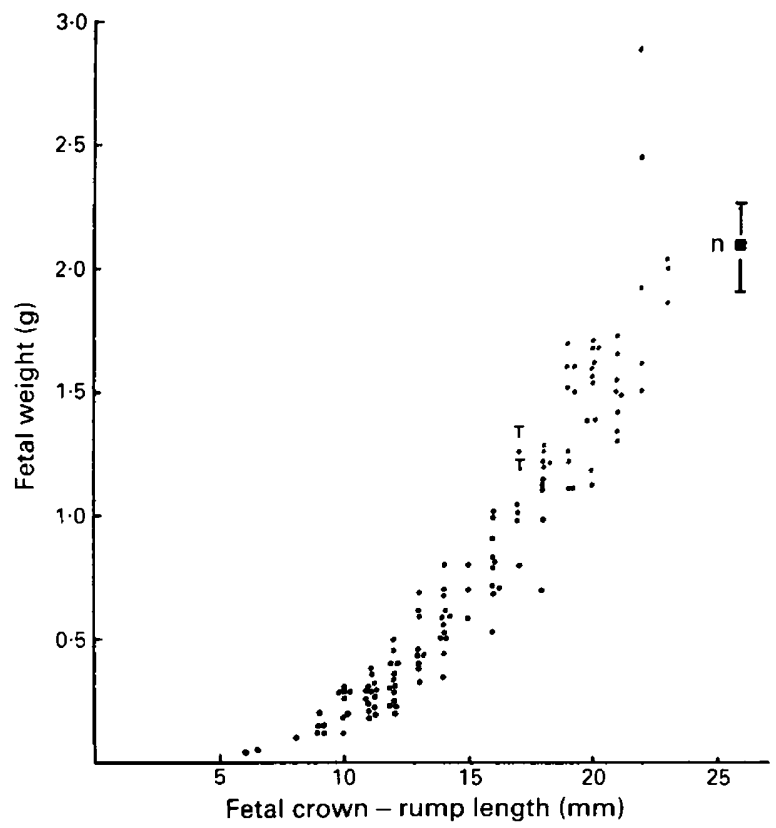

Fig. 1. Relationship between fetal weight and linear dimension in 1 neonatal and 131 fetal little brown bats. The values for 1 pair of twins are shown $(T)$ and 1 neonate, weighed within $5 \mathrm{~h}$ after birth (n). For comparison, the mean weight $(\boldsymbol{C})$ and standard deviation for 19 neonates of this species, obtained by Smith (1956), are shown.

There was a wide distribution of CR lengths in animals captured on a given day, spanning early May to late June, and so date of capture was of no use in defining stage of pregnancy.

Most fetuses of $>9 \mathrm{~mm}$ CR were weighed and weight bore an exponential relationship to the linear dimension (Fig. 1). A single instance of twin pregnancy was detected; each fetus measured $17 \mathrm{~mm} \mathrm{CR}$ and the combined fetal weight was $2.55 \mathrm{~g}$. This can be related to the weight of the pregnant mother before anaesthesia being $9 \cdot 9 \mathrm{~g}$. Each of the fetuses was heavier than the norm for their CR class.

The heaviest fetus weighed $2.88 \mathrm{~g}$ (CR $22 \mathrm{~mm}$ ) and was obtained from a $9.4 \mathrm{~g}$ animal. A single neonate of $2.08 \mathrm{~g}$ (CR $25 \mathrm{~mm}$ ) was collected along with its $6.6 \mathrm{~g}$ lactating mother. This maternal weight is comparable to the average maternal weight of all females with uteri smaller than $1.5 \mathrm{~mm}$ but it is in the lower range of weights of a total of 14 animals collected post partum. The heaviest pregnant female $(10.3 \mathrm{~g})$ was carrying a $22 \mathrm{~mm} \mathrm{CR}$ fetus of $1.65 \mathrm{~g}$, a fetal weight that was close to the mass growth curve for that stage of pregnancy (Fig. 1).

Plasma concentrations of progesterone are related to the $\mathrm{CR}$ data, measured or estimated as explained earlier, in Fig. 2. Concentration increased exponentially to $29.6 \mathrm{ng} / \mathrm{ml}$ (geometric mean) by the time $\mathrm{CR}$ reached $8 \mathrm{~mm}$. There was an approximate doubling in concentration for every $2 \mathrm{~mm}$ of fetal growth. The concentrations again doubled between fetal CR of 8-16 mm then remained relatively steady at about $65 \mathrm{ng} / \mathrm{ml}$ until term. Considerable variation was evident within fetal CR groups and was examined by multivariate analysis with progesterone concentration as the dependent variable. This variation could not be statistically attributed to known factors associated with collection of the samples, e.g. year or date of capture, habitat, interval from capture to sampling, or being held at $21^{\circ} \mathrm{C}$ or $5^{\circ} \mathrm{C}$. Some individual observations, indicated in Fig. 2, are noteworthy. In one animal with a uterine length of $5 \mathrm{~mm}$, blood and tissue fragments were observed in the uterine lumen and maternal progesterone concentration was $2.6 \mathrm{ng} / \mathrm{ml}$, a value within the range of samples obtained from all animals excluded from analysis because uterine 


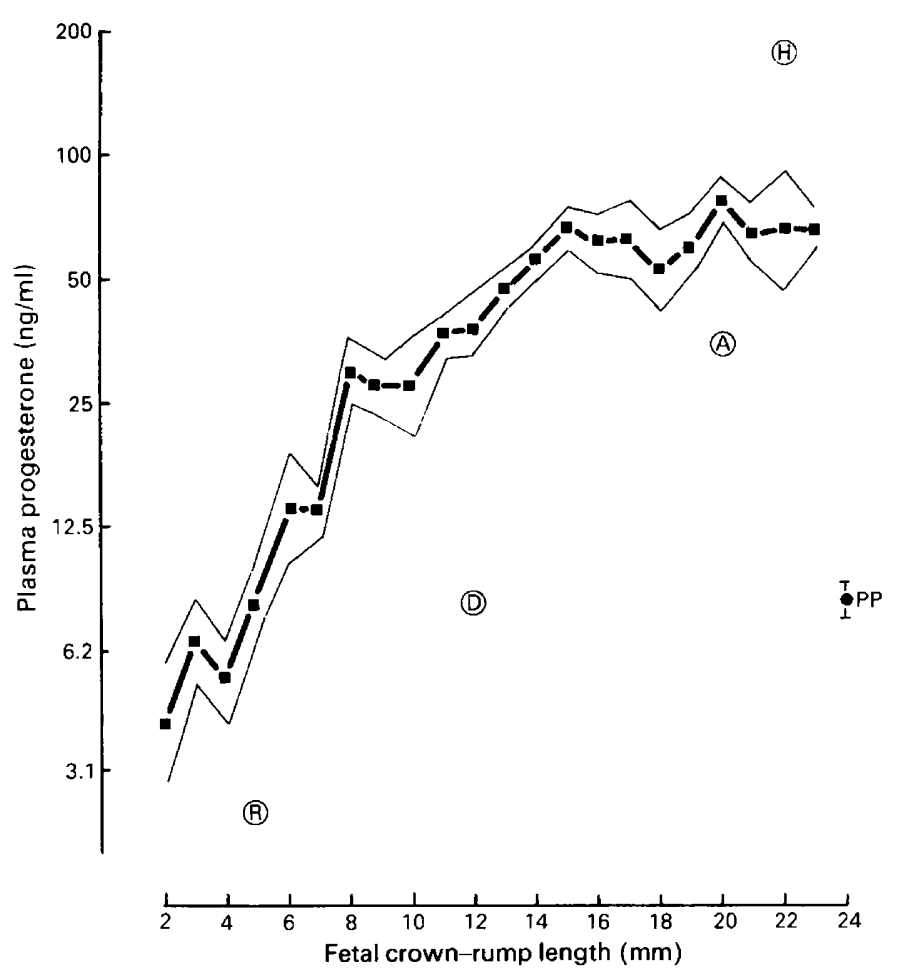

Fig. 2. Maternal plasma concentrations of progesterone in little brown bats. Values are geometric means and the outer lines define \pm 1 s.e.m. computed on log-transformed observations. The mean \pm s.e.m. for 14 post-partum bats are indicated (PP) as are uterine length of $5 \mathrm{~mm}$ with remnants of a conceptus (R), dead fetus of $12 \mathrm{~mm}$ CR length (D), animal aborting at sampling (A) and highest concentration measured $(174 \mathrm{ng} / \mathrm{ml})(\mathrm{H})$.

length was $<1.5 \mathrm{~mm}$ (range $2-10 \mathrm{ng} / \mathrm{ml}$ ). In one animal, a dead fetus of $12 \mathrm{~mm} \mathrm{CR}$ was recovered; maternal progesterone was $8.2 \mathrm{ng} / \mathrm{ml}$ compared to the $12 \mathrm{~mm} \mathrm{CR}$ geometric mean of $27.5 \mathrm{ng} / \mathrm{ml}$. The highest measured concentration was $174.5 \mathrm{ng} / \mathrm{ml}$ and was obtained from the heaviest female collected, noted above as having a $22 \mathrm{~mm}$ CR fetus. Other samples in the $22 \mathrm{~mm}$ group, all presumably close to term, had values of $40.8-56.5 \mathrm{ng}$ progesterone $/ \mathrm{ml}$. Concentrations in the animal with twins were $123.7 \mathrm{ng} / \mathrm{ml}$, approximately twice the $17 \mathrm{~mm} \mathrm{CR}$ group geometric mean. The very early post-partum female had $11.6 \mathrm{ng}$ progesterone $/ \mathrm{ml}$ compared to the $\sim 65 \mathrm{ng} / \mathrm{ml}$ measured in all animals in late pregnancy. The lowest pre-partum concentrations from animals with fetuses of $>22 \mathrm{~mm}$ CR were in the range of $40-50 \mathrm{ng} / \mathrm{ml}$.

Concentrations of progesterone in 8 post-partum bats, most of which were lactating, ranged between 7.0 and $11.6 \mathrm{ng} / \mathrm{ml}$ with a geometric mean of 8.36 ; this is about $12.5 \%$ of the mean in late pregnancy.

Progesterone was determined in 34 placentas and the concentrations ranged between 43 and $964 \mathrm{ng} / \mathrm{g}$. The data are grouped by CR categories in Fig. 3 and related to the equivalent plasma concentrations for animals of comparable stages of pregnancy. The identity of individual hemiplacentas and the total placental weights for each of these specimens were not known. However, placental weights in the smallest CR category were approximately $30 \mathrm{mg}$ and the largest were $\sim 120 \mathrm{mg}$. In the $13-21 \mathrm{~mm}$ CR groups, an average progesterone content would be $\sim 30 \mathrm{ng}$ in a $100 \mathrm{mg}$ placenta. Because the animals were exsanguinated, it is unlikely that maternal blood could account for more than $\sim 10 \%$ of the wet weight of the placenta. At this stage of pregnancy, $10 \mu \mathrm{l}$ 


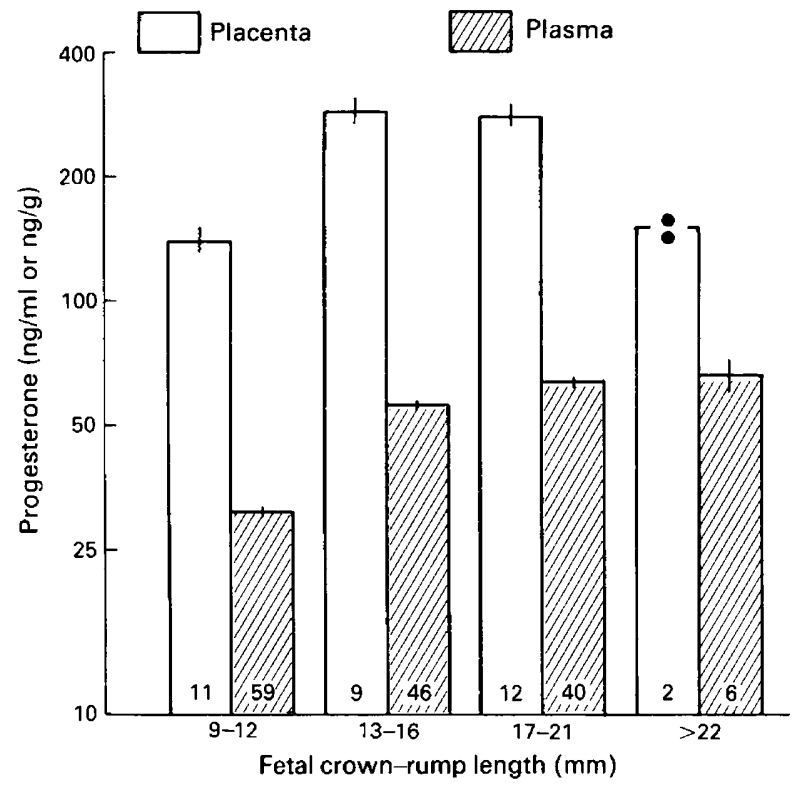

Fig. 3. Comparison of placental and maternal plasma concentrations of progesterone. Data are grouped on the basis of the crown-rump length of the fetus. The bars represent geometric means \pm s.e.m. (note the logarithmic ordinate) and the number of observations is shown at the bottom of each bar.

plasma contains $<1 \mathrm{ng}$ progesterone (Fig. 3) so the placental content of progesterone cannot be simply due to the blood.

\section{Discussion}

From a total of 303 animals captured during May to June when little brown bats are pregnant in the Ithaca locality, 17 were excluded because pregnancy was not confirmed, 4 animals were carrying dead fetuses or abortuses, 1 animal had twin fetuses, 1 animal had a still-wet neonate and, of 14 post-partum females, 12 were actively lactating.

Fetal growth, based on both weight and CR measurements (Fig. 1) cannot be related with absolute confidence to the stage of pregnancy in days. The exponential relationship between weight and CR spans the stages between $6 \mathrm{~mm}$ and $23 \mathrm{~mm}$. Weights for the $23 \mathrm{~mm}$ group are comparable to those reported by Smith (1956) for 19 neonates of this species $(2.08 \pm 0.18 \mathrm{~g})$. The single neonate collected in the present study was indeed of an appropriate weight $(2.08 \mathrm{~g})$ but was longer (CR $25 \mathrm{~mm}$ ) than any of the fetuses, even the two that were considerably heavier. For most species, fetal weight increases exponentially with days of gestation and so, with some reservations, our approximation of CR length to stage of pregnancy is probably valid.

Two of the most mature fetuses were markedly heavier than reported birth weights for this species. The heaviest at $2.88 \mathrm{~g}$ is in excess of four standard deviations above the mean neonatal weight reported by Smith (1956). Each of the twins was of slightly greater than normal weight for their $17 \mathrm{~mm} \mathrm{CR}$ class. Although the fetuses were immature, their combined weight was already $35 \%$ of the adjusted maternal weight (maternal minus fetal). Other products of conception would further increase this estimate of the weight burden of pregnancy. For the largest fetus, its weight alone represented $44 \%$ of the maternal weight, adjusted as above. Given the magnitude of fetal weight, it is not unexpected that twin fetuses have been detected on only three previous occasions (Wimsatt, 1945). 
Despite the total blood volume of these animals being $<1 \mathrm{ml}$, sufficient plasma was obtained to permit progesterone determinations on duplicate aliquants. In several of the bats with uterine length $<2 \mathrm{~mm}$, the assay of $5 \mu \mathrm{l}$ samples was beyond the limit of sensitivity. However, the pregnant status of these animals was not established so this study does not consider the very earliest stages of the initiation of pregnancy. The reader is referred to Buchanan \& YoungLai (1986) for a comprehensive description of changes in progesterone concentrations related to the stage of development of the conceptus of little brown bats. They aroused torpid bats from a hibernaculum to synchronize ovulation and determined the stage of development through early embryogenesis along with measurement of plasma progesterone. The data of Buchanan \& YoungLai (1986) pertaining to post-embryonic stages of development were obtained from field collections comparable to ours. Their plasma progesterone measurements from $16 \mathrm{mid}$ - to late-pregnant and 10 lactating bats are quite similar to those presented here although our data are more comprehensive and categorized into smaller intervals across the later part of pregnancy.

The substantial increases in plasma concentrations of progesterone precede the most rapid phase of fetal growth. There was marked variation in concentrations at a given CR stage that could not be accounted for in multivariate analysis, giving consideration to a variety of recorded aspects related to the collection of samples (detailed under 'Results'). Despite the individual variation, the geometric mean concentrations remained relatively stable over the second half of pregnancy. As in the study of Buchanan \& YoungLai (1986), there was no indication of any mid-pregnancy or prepartum decrease in concentrations of progesterone. Because of variation in the time of ovulation of field-collected animals (Tuttle \& Stevenson, 1982), the expected time of parturition cannot be predicted. Concentrations measured in the animals with fetuses of CR 22 and $23 \mathrm{~mm}$ ranged between 40 and $178 \mathrm{ng} / \mathrm{ml}$, the latter being the highest value obtained in this study.

Elevated concentrations of progesterone are obviously pregnancy-related. Concentrations fell in the post-partum bats to about $12.5 \%$ of the pre-partum mean. In the only animal that gave birth between capture and sampling $5 \mathrm{~h}$ later, progesterone concentrations were $11.6 \mathrm{ng} / \mathrm{ml}$. Lactogenesis had occurred in this animal, so it might be argued that progesterone concentrations had decreased some hours earlier.

Sub-normal concentrations of progesterone were measured in 3 cases of pregnancy failure. While these individual samples were far below the corresponding geometric means, they were not gross outliers because similar concentrations were obtained from animals that were superficially normal.

The unexpectedly high circulating concentrations of progesterone and preliminary histochemical evidence of $3 \beta$-hydroxysteroid dehydrogenase activity in placenta (M. Blake \& W. A. Wimsatt, unpublished results) prompted the investigation of placental concentrations of this steroid. Progesterone was present in amounts far in excess (15- to 20-fold) of what could be explained by the blood content of the tissues. Concentrations, expressed on a weight of tissue basis, were reduced in the 2 specimens collected from the largest fetuses. In the animal that had delivered its young and initiated lactation within a few hours of capture, progesterone concentrations in plasma had declined and this presumably reflected loss of placental production of the steroid. If this change precedes parturition, then some control must be exerted on the steroidogenic function of the placenta.

Buchanan \& YoungLai (1986), who obtained similar plasma concentrations from the same species collected from a similar environment, provide a thorough comparison of the data from little brown bats with reports of steroid values in other species of bats. Racey \& Swift (1981) have suggested that high concentrations of progesterone could confer metabolic advantages via thermogenic actions of the steroid. The duration of pregnancy is lengthened in animals maintained at low ambient temperatures. Racey (1973) demonstrated that fetal development was delayed and gestation was prolonged in pregnant pipistrelle bats that were deprived of food and maintained in the cold. The bats studied in the present work were collected from nursery locations where daytime temperatures were frequently as high as $40^{\circ} \mathrm{C}$; this may reflect selection by the animals of an 
environment in which elevated body temperatures are readily maintained, despite the nutrient drain for fetal anabolism. Finally, the physical bulk of the conceptus, up to a $50 \%$ increment over that of the dam, has to be accommodated within the uterus. Currie (1979) has suggested, on the basis of studies in rabbits, that progesterone can function to maintain distensibility of the uterus and constrain the development of reactive tension in response to deformation.

Whatever the major function of this steroid may be, thermogenic, uterine accommodation or the widely accepted role in eutherians of suppressing uterine excitability, the little brown bat is able to establish chronically elevated concentrations of progesterone as part of its adaptation to the pregnant state. As one of the smallest mammals, it is clear that, with the benefit of placental production of the hormone, exceedingly high plasma concentrations of progesterone are maintained throughout late pregnancy. It remains to be determined whether production of the steroid declines as part of the preparation for parturition, or whether the decrease in plasma concentrations is merely a consequence of the disruption of placental function at delivery.

We thank Frank Michel and Linda Isaman for assisting with the hormone assays.

\section{References}

Buchanan, G.D. \& YoungLai, E.V. (1986) Plasma progesterone levels during pregnancy in the Little Brown Bat Myotis lucifugus (Vespertilionidae). Biol. Reprod. 34, 878-884.

Currie, W.B. (1979) Uterine excitability and distensibility influenced by treatment in vitro with progesterone. Anim. Reprod. Sci. 2, 225-238.

Fenton, M.B. \& Barclay, R.M.R. (1980) Myotis lucifugus. Mammalian Species 142, 1-8.

Fitzgerald, J. \& Butler, W.R. (1982) Seasonal effects and hormonal patterns related to puberty in ewe lambs. Biol. Reprod. 27, 853-863.

Racey, P.A. (1973) Environmental factors affecting the length of gestation in heterothermic bats. J. Reprod. Fert., Suppl. 19, 175-189.
Racey, P.A. \& Swift, S.M. (1981) Variations in gestation length in a colony of pipistrelle bats (Pipistrellus pipistrellus) from year to year. J. Reprod. Fert. 61, 123-129.

Smith, E. (1956) Pregnancy in the Little Brown Bat. Am. J. Physiol. 185, 61-64.

Tuttle, M.D. \& Stevenson, D. (1982) Growth and survival of bats. In Ecology of Bats, pp. 105-150. Ed. T. H. Kunz. Plenum Press, New York.

Wimsatt, W.A. (1945) Notes on breeding behavior, pregnancy and parturition in some vespertilionid bats of the eastern United States. J. Mammal. 26, 23-33.

Received 10 August 1987 